\title{
Experimental study of the Rhone plume. Part I: physics and dynamics
}

\author{
Pierre BROCHE ${ }^{\text {a }}$, Jean-Luc DEVENON a, Philippe FORGET a, Jean-Charles de MAISTRE a, \\ Jean-Jacques NAUDIN ${ }^{b}$, Gustave CAUWET ${ }^{b}$ \\ "Laboratoire de sondages électromagnétiques de l'environnement terrestre (LSEET) \\ CNRS, université de Toulon, BP 132, 83957 I a Garde cedex, France \\ ${ }^{\mathrm{b}}$ Observatoire océanologique de Banyuls, BP 44, 66651 Banyuls-sur-Mer, France
}

(Revised 14 April 1998, accepted 28 April 1998)

\begin{abstract}
The complicated dynamic processes occurring when fluvial waters mix with marine waters control the nature and the fluxes of materials exported by rivers to the sea. Understanding these processes is of primary importance in evaluating budgets. In wide-open estuarine situations these processes take place under the influence of an intense turbulence induced by tides. Conversely, the Rhone waters spread into the Mediterranean Sea in the form of an easily distinguishable buoyant plume often extending far offshore from the mouth of the river. The aim of this study is to describe the dynamic and hydrological fields on the basis of eulerian VHF radar mapping of surface currents coupled with lagrangian in situ physical or geochemical measurements. This paper focuses mainly on physical processes. Data analysis provides an insight into the typical scales of variability of the phenomena, either vertically or horizontally. It is shown that morphological fluctuations can occur (mainly in orientation and offshore extent) according to wind and outflow forcing conditions, and that the vertical structure variations can range from an almost unaltered two-layer distribution to an evolving and deepening mixed layer situation, or even to a more complex superimposed multi-layered structure. The simultaneous examination of radar maps and lagrangian drifter tracking allows the main dynamic tendencies of the Rhone plume to be sketched out. (O) Elsevier, Paris
\end{abstract}

\section{river plume / VHF radar / Rhone / dynamics}

Résumé - Étude expérimentale du panache du Rhône. Partie I : physique et dynamique. La zone de mélange entre les eaux d'un fleuve et les eaux marines est le siège de processus dynamiques complexes qui conditionnent la nature et les flux de matières apportées au milieu marin. La compréhension de ces mécanismes est primordiale pour effectuer des bilans. Contrairement aux estuaires où la dilution est induite par une turbulence intense entretenue par les flux entrant et sortant de marée, les eaux du Rhône s'épanchent en Méditerranée sous forme d'un panache flottant sur de grandes distances au large de l'embouchure. L'objet du présent travail est d'appréhender les champs dynamiques et hydrologiques de cette structure au moyen de cartographies de vitesses eulériennes de courant superficiel par radar VHF et au moyen de mesures lagrangiennes in situ physiques et géochimiques. Cet article est consacré aux processus physiques. L'analyse des données permet de cerner la variabilité du phénomène, tant horizontale que verticale. Les fluctuations de morphologie (orientation et extension vers le large) du panache en fonction des conditions météorologiques et de débit fluvial sont mises en évidence, ainsi que les variations de sa structure verticale, allant d'une structure bicouche pratiquement non altérée à une couche bien mélangée, de caractéristiques en évolution et d'épaisseur croissante, ou à une superposition multicouche plus complexe. L'examen simultané des cartes de courant et des données physiques lagrangiennes permet de dégager les grandes tendances du fonctionnement dynamique du panache du Rhône. (C) Elsevier, Paris

panache fluvial / radar VHF / Rhône / dynamique 


\section{INTRODUCTION}

The distribution and fate of dissolved and suspended matter in the coastal zone depend on the physical, chemical and biological changes which occur as freshwater is transferred from estuaries to the open sea. The behaviour of particulate matter during mixing is influenced by various balanced processes such as adsorption/desorption, floculation/disaggrcgation, production/grazing, uptake/ excretion or advection/settling [14, 19, 22, 28, 29]. The fertilizing action of rivers has been demonstrated at a number of shelves $[10,16,24,31]$ and the consequences for primary production have been well documented by remote sensing $[1,23]$, salinity and light limitation studies [19] and nutrient analysis [33]. All chemical and biological processes depend strongly on the physical properties of the fluid in which they occur. River flow [6, 7], wind [5, 18, 26], turbulent mixing [32] and tidal motion [27] are the main external forces in the biogeochemical processes in terms of their influence on the residence time [17] and the turbulent exchanges [9]. The various orders of magnitude of the characteristic time scales of physical, chemical and hiological processes are of particular importance for understanding and modelling cycling and fluxes of dissolved and suspended matter.

The interactions between physical and biogeochemical processes in river plumes are enhanced by the unsteady and stratified nature of the flow. They have been studied on seasonal time scales and large space scales. This paper and its companion [25] focus on the relationships at small spatial scales and short time scales between environmental conditions and particulate and dissolved matter transferred towards the coastal zone. They present and discuss experimental results obtained in the Rhone plume (French Mediterranean coast) in November 1994. This paper is devoted to the physical and dynamic characteristics of the plume. Biogeochemical mechanisms are considered in Naudin et al. [25].

At a river mouth where freshwater input runs into marine waters, a complex intrusion process occurs. It mainly depends upon the interaction between the buoyancyinduced momentum fluxes, which spreads the freshwater offshore, and the turbulent dilution and dissipation mechanisms, which reduce density and velocity differences between the two water masses. The balance between these two mechanisms depends upon the distance from the mouth and the turbulence intensity in the receiving basin. The situations encountered vary from a completely and almost immediately diluted intrusion in marine waters to an appar- ent lack of mixing of buoyant discharges, which take the form of a well-identified surface plume $[12,13,35]$. This is the case for the Rhone, where in general a thin upper layer (1 or $2 \mathrm{~m}$ ) is separated from the ambient water by a sharp transition where the salinity exhibits a jump of 10 or 20 and extends offshore over distances of the order of 20 or $30 \mathrm{~km}$. Mctcorological forces can significantly modify the size and the shape of the plume within time scales as short as a few hours. In particular, winds and waves can generate an efficient mixing which brings marine water into the plume, leading to the thickening of the surface layer and the smoothing of the salinity gradients.

Simultaneous samplings of both density and velocity fields are needed to understand the mechanisms governing the buoyancy and mixing balance and its evolution in time and space. A field campaign was then designed to collect liydrological and surface current velocity measurements in the Rhone plume area simultaneously. Surface current measurements are difficult because of the narrowness of the plume. Two techniques proved to be convenient in such conditions: VHF radar [8], and surface drifters [24]. A system of two VHF radars mapping the surface current was set up in the vicinity of the mouth of the Rhone. During the first and last weeks of November 1994, lagrangian measurements of velocity were performed from the R.V. Professeur Georges Petit by tracking surface drifters. During the trackings, in situ measurements of conductivity, temperature, reflectance [11] and concentration of several dissolved or suspended matters [25] were performed in the surface layer $(0$ to $10 \mathrm{~m})$. In fact, because of the meteorological conditions, in situ measurements were only made on 6 and from 21 to 25 November.

The paper is organized as follows: section 2 presents the area under study, the meteorological conditions and the instrumental procedures. Section 3 presents the general characteristics of the dynamics and of the morphology of a river plume and discusses the balance of the various forces acting on it. Sections 4 and 5 present the experimental results, emphasizing respectively the influence of the two main forcings: the river flow and the wind. Conclusions are drawn in section 6 .

\section{FIELD MEASUREMENTS}

\subsection{Environmental conditions}

The Rhone flow varies from 500 to $10000 \mathrm{~m}^{3} \mathrm{~s}^{-1}$ with an annual mean flow of $1715 \mathrm{~m}^{3} \mathrm{~s}^{-1}$. For the last twenty years the highest monthly mean flow has occurred in 
February (2355 $\mathrm{m}^{3} \mathrm{~s}^{-1}$ ) and the lowest in August $\left(1047 \mathrm{~m}^{3} \mathrm{~s}^{-1}\right.$ ). In November the autumnal rains over the Alps and Cévennes result in above average river flows. Hourly flow measurements are regularly taken at Beaucaire, $65 \mathrm{~km}$ upstrean from the mouth, by the "Compagnie Nationale du Rhône". They show several flood events during the selected period (figure la): a 50 year flood $\left(10000 \mathrm{~m}^{3} \mathrm{~s}^{-1}\right)$ on 6 and 7 November, followed by less important episodes, in particular from 10 to 13 November (4000 to $5000 \mathrm{~m}^{3} \mathrm{~s}^{-1}$ ), then on 20 and 21 November (about $2500 \mathrm{~m}^{3} \mathrm{~s}^{-1}$ ).

The wind velocity at ten metres was measured at the Salin-de-Giraud station, near the shore (figure /b).
Results are representative of the typical meteorological conditions in this region, with a majority of well established northerly or northwesterly winds over $5 \mathrm{~m} \mathrm{~s}^{-1}$, an episode of strong southeasterly wind and a few periods of light sea breezes.

Currents in the receiving basin are mainly controlled by local meteorological conditions and by the LiguroProvencal-Catalan (LPC) current which sometimes flows westwards over the shelf [21]. A thermocline begins to develop in April or May, then strengthens and deepens throughout the summer. Typically, wind and wave mixing homogenize surface waters down to 60 to $80 \mathrm{~m}$ depth at the end of October. Maregraphic measurements made at a

\section{(a) RIVER FLOW $(\mathrm{m} 3 / \mathrm{s})$}

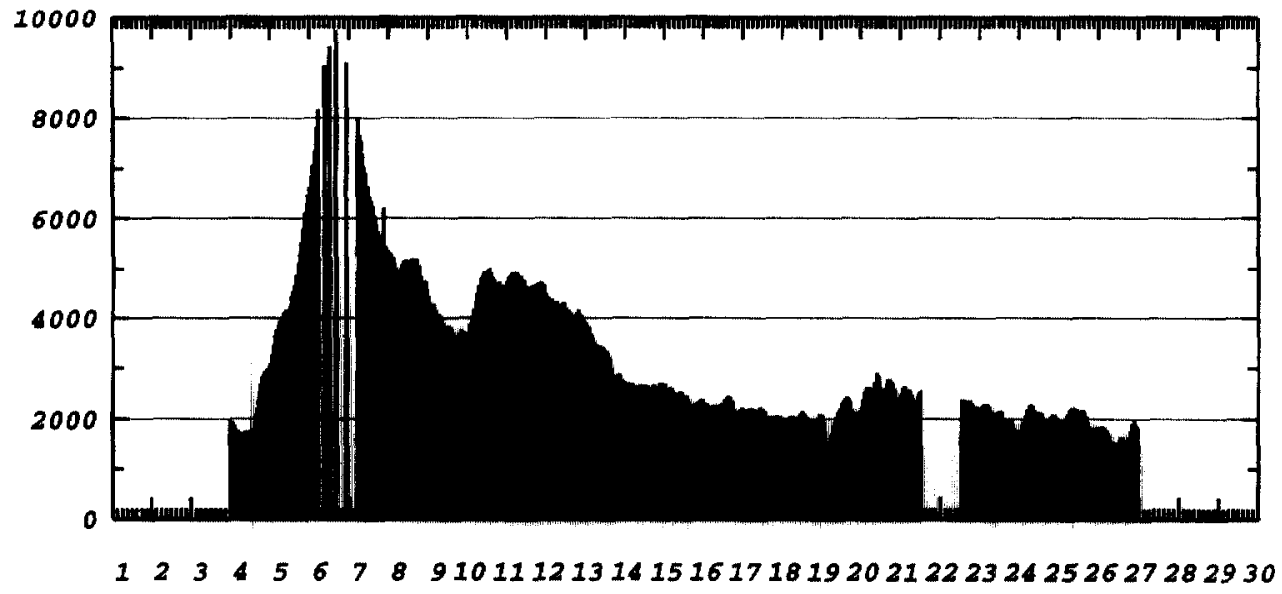

(b) WIND SPEED $(\mathrm{m} / \mathrm{s})$

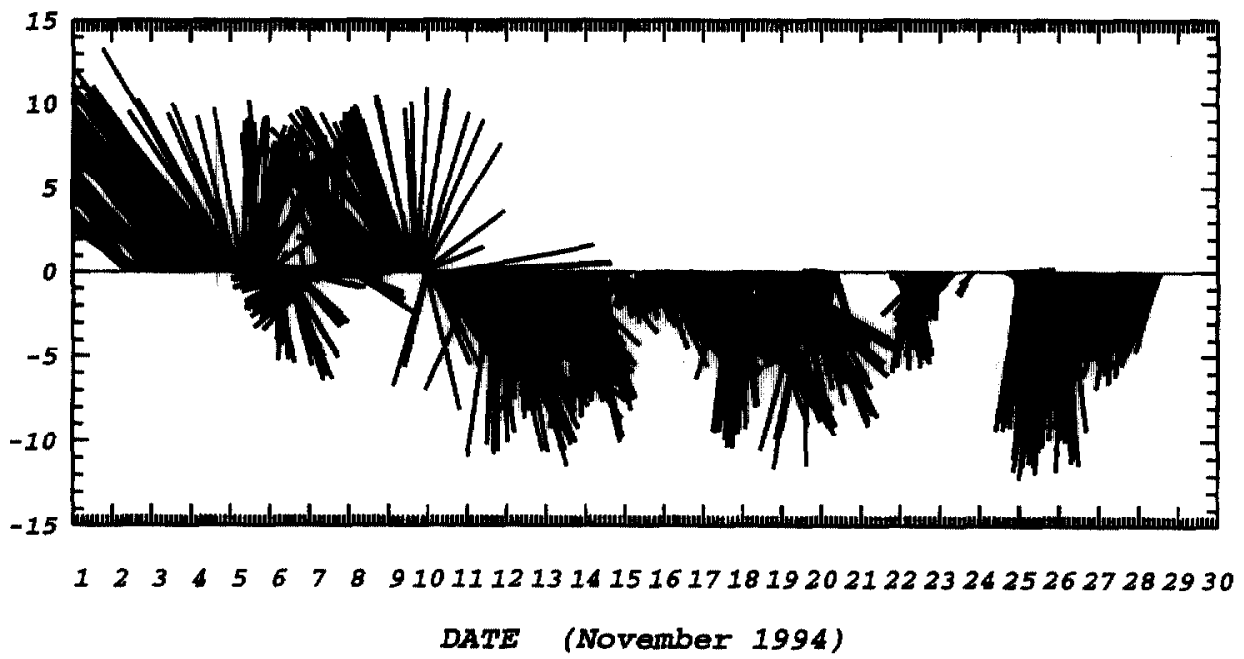

Figure 1. (a) River flow in November 1994. (b) Wind speed at the Salin-de-Giraud radar station in the same period. 
shore station within the study area by the "Compagnie des Salins du Midi" exhibited a dominant semi-diurnal tidal component of less than $10 \mathrm{~cm}$ in amplitude. The associated currents were thus very slow and will not be considered in this study.

\subsection{VHF radar measurements}

Two VHF radars working respectively at 47.8 and $45 \mathrm{MHz}$ were set up on the shoreline, in Salin-de-Giraud and in Martigues (figure 2a). The two stations were $25 \mathrm{~km}$ apart. At a given radar wavelength $\lambda_{i}$, the echo from the sea is produced by surface waves of wavelength $\lambda_{i} / 2$ propagating towards or receding from the radar (the so-called "Bragg waves"). The Doppler shift of the echo is used to measure the phase velocity of the Bragg waves. By comparing it with the theoretical value expected in the absence of current $\left(v_{b}=\sqrt{g \lambda_{i} / 4 \pi}\right)$, the radial component of the current velocity can be estimated $[3,30]$. More precisely [4] the measured quantity is the radial component of the current velocity averaged:

- in time, over the delay necessary to compute the sea echo Doppler spectrum with convenient frequency reso-
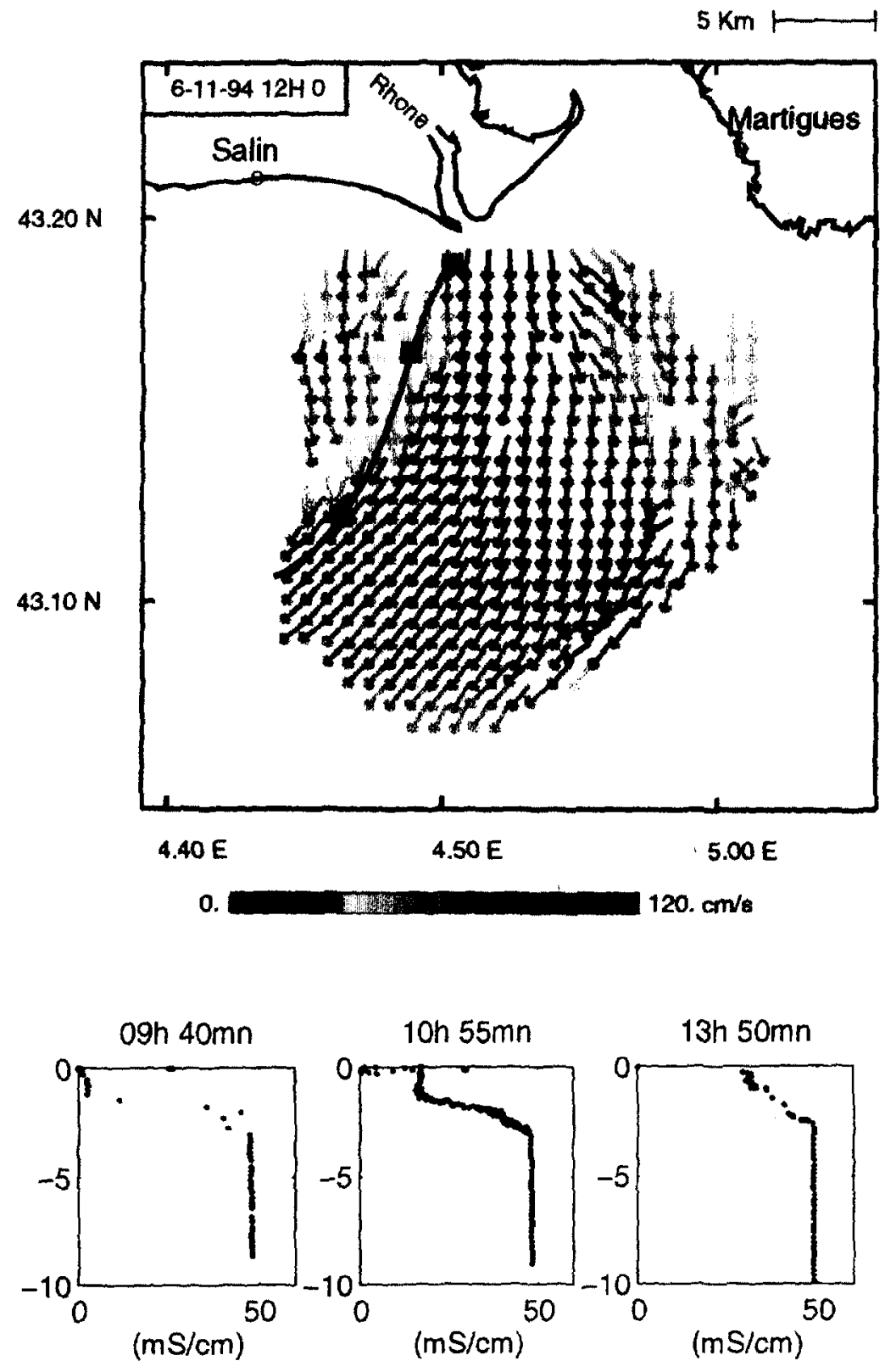

Figure 2. (a) Radar map of the surface current vector at $12 \mathrm{~h}$ (local time). 6 November. The two radar stations are indicated (Salin-deGiraud as "Salin" and Martigues). Arrows give the direction of the current and the colour scale represents the speed. The trajectory of the drifter is indicated by a continuous line beginning in front of the mouth. Black squares indicate the location of the 3 CTD profiles shown in part (b).

(b) Three profiles of conductivity along the trajectory of the driftes. 
lution and number of degrees of freedom: this delay was seven minutes;

- in depth, over the layer which is hydrodynamically influenced by the Bragg waves. It is generally admitted that the measured velocity is the true velocity of the current at the depth of $\lambda_{i} / 8 \pi$, about $25 \mathrm{~cm}$ in this case;

- in horizontal dimensions, over an area determined by the radar space resolution, which depends upon the technical characteristics of the system: pulse length, antennae dimensions. This area is proportional to the distance to the radar. For the present case it varied from one to several square kilometres.

In any area simultaneously covered by the two radars, the two radial measurements can be combined to give the two cartesian components of the current velocity vector. This was done at the nodes of a cartesian grid with a mesh of $1 \times 1 \mathrm{~km}^{2}$ extending up to $30 \mathrm{~km}$ from each radar. Current vector maps were generally produced every $30 \mathrm{~min}$. Sometimes data were missing on a more or less important part of the grid, especially during calm wind periods when the signal-to-noise ratio was too weak. The accuracy of the cartesian components depends on the radar characteristics (mainly the integration time) and on the crossing angle of the two radar beams. In the present conditions it was estimated to be of the order of $5 \mathrm{~cm} \mathrm{~s}^{-1}$.

\subsection{Drifter tracking}

The sampling strategy for biogeochemical analyses was based on the lagrangian motion of surface drifters [24]. The drifters were designed to follow the water movement at a mean depth close to the depth sensed by the radars $(25 \mathrm{~cm})$. Drifters were released on November $6,21,22$, 23,24 and 25 , at about $2 \mathrm{~km}$ south of the mouth. The quasi-continuous tracking from the ship for several hours each day supplied direct data about the near-surface current velocity. The trajectories and the associated velocities (computed by a polynomial regression) are plotted in figure $3 \mathrm{a}$ and $3 \mathrm{~b}$. These measurements supplied both a
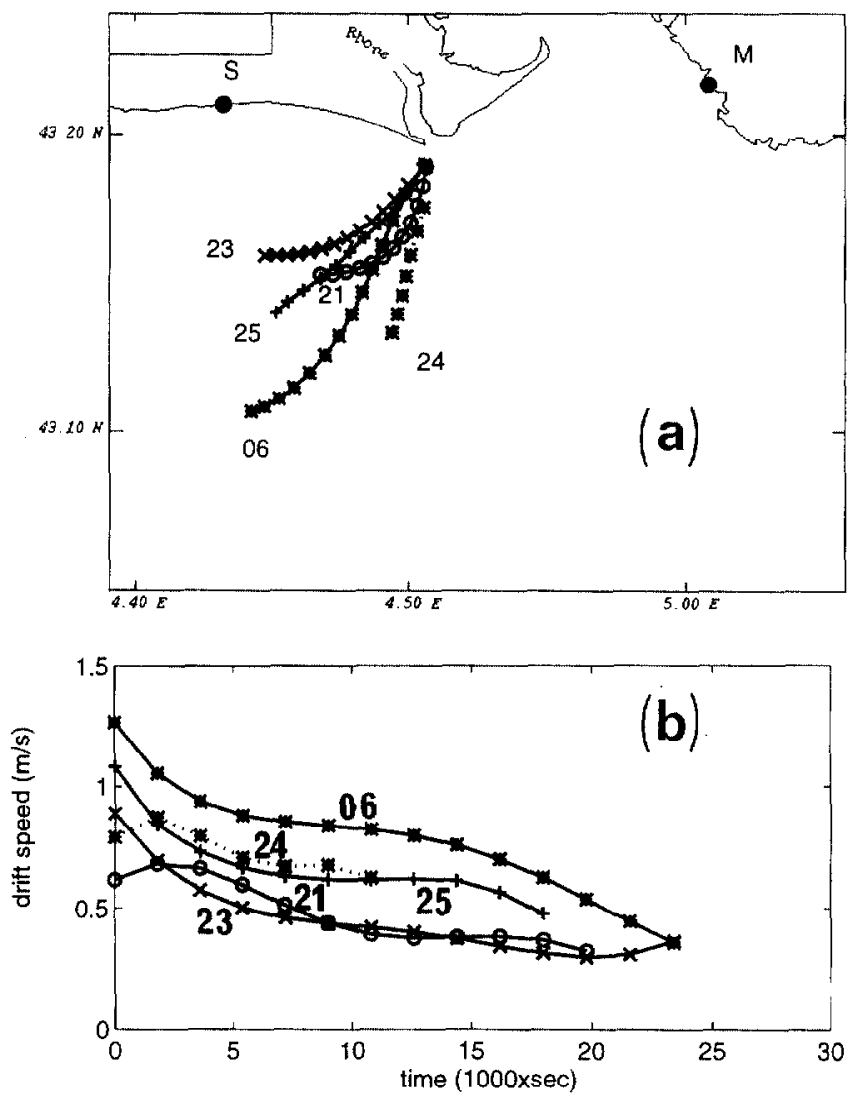

Figure 3. (a) Trajectories of the drifters on 6,21, 23, 24 and 25 November. (b) Speed of the drifters as function of the time after the release. Dates are indicated on the curves. 
validation of the radar maps and in situ information about the plume kinematics when the wind was too light and the radar echoes too weak, specially during the calm period of 21-24 November.

\subsection{In situ data}

The CTD measurements (Conductivity and Temperature as functions of Depth) were made from the ship. The sampling frequency $(3 \mathrm{~Hz})$ and the vertical movement of the CTD sensor were adjusted for the best possible resolution of the stratification of the first ten metres of the surface water. Caution was taken to prevent any perturbation of the surface layer by the ship. The possible presence of a deeper thermocline was not investigated. Two types of experiment were carried out:

- conductivity and temperature protiles following the drifters: these measurements were made each day of drifter tracking $(6,21,22,23,24$ and 25 November). About ten profiles were measured along each trajectory;

- conductivity and temperature profiles along the $20 \mathrm{~m}$ isobath within the shortest time delay possible (less than $2 \mathrm{~h}$ ) to sample the transverse structure of the plume These measurements were made on 22 and 24 November.

\section{PLUME DYNAMICS AND MORPHOLOGY}

The data collected during the experiment supply a detailed description of the horizontal and vertical morphology of the plume. This morphology will be discussed in the following two sections, referring to the characteristic influences of the main forces acting on the plume: river flow and wind. In this section, some general ideas concerning plume dynamics are presented.

Assuming quasi-horizontal motions, the main forces acting on a water particle of unit mass are:

- the inertial force $\vec{f}_{i}$, with a transverse (i.e. perpendicular to the streamlines) component (the centrifugal force) given by: $f_{r}=U^{2} / R$, where $U$ is the flow velocity and $\mathrm{R}$ the radius of curvature of the trajectory, and a longitudinal (i.e. parallel to the streamlines) component $f_{l}=d U / d t$

- the Coriolis force $\overrightarrow{f_{c}}$, which is transverse and given by: $f_{c}=f U$, where $f$ is the Coriolis parameter (close to $10^{-4} s^{-1}$ ). The general orientation of the flow is southwards and the zonal component of the Coriolis force points westwards;
- the horizontal pressure force $\vec{f}_{p}$ associated with the horizontal buoyancy gradient. A strongly stratified plume with sharp lateral boundaries can be considered as a surface layer of thickness $H$ and density $\left(\rho_{0} \rightarrow \Delta \rho\right)$ floating above the ambicnt water of density $\rho_{0} \cdot f_{p}$ can then bc expressed as [12]:

$\overrightarrow{f_{p}} \approx-\vec{\nabla}\left(g^{\prime} H\right)=-\vec{\nabla}\left(C^{2}\right)$

where $g^{\prime}=g\left(\Delta \rho / \rho_{0}\right)$ is the reduced gravity and $C=\sqrt{g^{\prime} H}$ is appproximately the internal wave velocity. In the transverse direction $\vec{f}_{p}$ has opposite orientations on the two sides (west and east) of the plume and it roughly points westwards and eastwards respectively:

- the wind force $\overrightarrow{f_{w}}$ whose average amplitude in the surface layer is approximately given by $\tau / \rho_{0} H$, where $\tau$ is the wind stress. $\tau$ can classically be modelled as $\rho_{a} C_{d} w^{2}$, where $\rho_{a}$ is the air density, $C_{d}$ a drag coefficient (order of magnitude: $1.3 \times 10^{-3}$ ) and $w$ the wind velocity;

- the friction force $\vec{f}_{f}$ associated with mixing between the brackish surface water and the ambient marine water. $\vec{f}_{f}$ is mainly longitudinal and opposite to the flow.

Two non-dimensional numbers are commonly used to describe the relative order of magnitude of the transverse components of $\overrightarrow{f_{r}}, \overrightarrow{f_{c}}, \overrightarrow{f_{p}}$ :

- the Rossby number can be defined as the ratio of the centrifugal force to the Coriolis force: $N_{R}=f_{r} / f_{C}=U^{2}$ / $R f U=U / R f$.

$N_{R}$ is also the ratio of the inertial radius to the curvature radius $R$;

- the densimetric Froude number can be defined as the ratio of the centrifugal force to the transverse pressure force: $N_{t}=f_{r} / f_{p}$. In strongly stratified situations where the pressure force can be approximated by $-\vec{\nabla}\left(C^{2}\right)$, and assuming that the curvature radius $R$ is a characteristic transverse scale for $C^{2}$, the densimetric Froude number can be expressed as the square of the ratio of the water velocity $U$ to the internal wave velocity. It may also be written as:

$N_{F}=\frac{U^{2}}{g^{\prime} H}=\frac{(U / H)^{2}}{g /\left(\rho_{0} \cdot \Delta \rho / H\right)}=\frac{(\partial U / \partial z)^{2}}{g / \rho(\partial \rho / \partial z)}$

and it can be interpreted as the inverse of a Richardson number. Moreover $U^{2} / H$ is a rough evaluation of the (longitudinal) friction force and $N_{F}$ appears as the ratio of the friction force to the buoyancy force ( $g^{\prime}$ per unit IIlass). 
Referring to the centrifugal force, Coriolis and horizontal pressure forces respectively scale as $Q_{R}=1 / N_{R}$ and $Q_{F}=1 / N_{F}$. For simplicity, the ratio of the wind force to the centrifugal force is expressed as:

$Q_{w}=f_{w} / f_{r}=\frac{\rho_{a}}{\rho} C_{d}\left(\frac{w}{U}\right)^{2} \frac{R}{H}=K_{w}\left(\frac{w}{U}\right)^{2} \frac{R}{H}$

where $K_{w}$ is of the order of $1.7 \times 10^{-6}$. Some rough estimates of $Q_{R}, Q_{F}, Q_{k}$ along drifter trajectories have been computed from the data (water and wind velocities, curvature of the trajectory and salinity profile). They are given in table $I$. Coriolis and inertial forces are generally dominant (i.e. the plume is controlled by the water flux), except for 25 November where the wind influence is dominant. In the next two sections, we will study these two regimes of the plume more precisely.

Close to the mouth, the Froude number $N_{F}=1 / Q_{F}$ is always found to be greater than unity (table $I$ ). In Garvine's terminology [12] the flow is supercritical and the plume is dynamically unstable [35]. In addition, the well marked character of the lateral boundaries of the plume appears on radar maps as velocity discontinuity lines associated with a dynamic convergence. CTD measurements across the plume (made along the $20 \mathrm{~m}$ isobath) also emphasize this fairly marked hydrological frontal zone where salinity undergoes an increase of about 10 to 15 (e.g. see figure $4 \mathrm{~b}$ below). Surcriticity and lateral fronts are two aspects of the same hydrodynamical regime the plume flow when mixing is weak: the brackish water floats and spreads above the ambient water, keeping sharp limits in both horizontal and vertical directions. Such behaviour is significantly different from what is observed either in larger areas where the dilution and mixing of the plume are more important or at the mouth of tide-dominated estuaries where the supercritical regime (defined as above) is restricted to the estuary itself [15].

\section{INFLUENCE OF THE RIVER FLOW}

The influence of the river flow on the plume is illustrated by the data of 6 November (figure 2), 21 November (figure 5) and 22 November (figure 4).

The ascending phase of a 50 year flood occurred on 6 November. The flow at the mouth was estimated to be $7000 \mathrm{~m}^{3} \mathrm{~s}^{-1}$ at $12 \mathrm{~h}$. A light northwest wind (less than $5 \mathrm{~m} \mathrm{~s}^{-1}$ ) turned to west in the afternoon. The plume is evident on the radar maps of the surface current (figure 2a) up to the radar maximum range $(30 \mathrm{~km})$. Two fronts of velocity discontinuity are observed at the eastern and western boundaries of the plume. Drifter velocity is greater than $120 \mathrm{~cm} \mathrm{~s}^{-1}$ near the mouth and decreases as the plume widens (figure 3). CTD profiles (figure 2b) show a well identified surface water mass separated from the ambient sea water by a strong vertical gradient of conductivity and temperature. At the beginning of the trajectory the thickness of the surface layer is about $2 \mathrm{~m}$. It remains almost constant along the first part of the trajectory and decreases slightly as the vertical hydrological gradients are progressively smoothed.

On 21 and 22 November the flow was in the range of 2300-2100 $\mathrm{m}^{3} \mathrm{~s}^{-1}$ i.e. three times less than on 6 Nuvember. The wind was light, almost calm on 21 November and less than $5 \mathrm{~m} \mathrm{~s}^{-1}$ on 22 November. The current map of 22 November (figure 4a) shows a well defined plume whose shape and extension are quite similar to those observed on 6 November. The drifter trajectory on 21 November (figure 5a) is shorter than on 6 November due to the smaller velocities: the maximum velocity within the plume is of the order of $70 \mathrm{~cm} \mathrm{~s}^{-1}$ (figure 3). CTD profiles (figure 5b) show that the plume keeps an almost constant thickness of about $1 \mathrm{~m}$ along the trajectory.

It can be concluded that variations in the flow intensity have only a small influence on the shape of the plume and

Table I. Scaling of the various forces acting on the plume. The scaling is referred to the centrifugal force (first column). Coriolis, pressure and wind forces are respectively scaled by $Q_{R}$ (inverse of the Rossby number), $Q_{F}$ (inverse of the densimetric Froude number) and $Q_{w}$. For each of these forces the three columns correspond respectively to the first and the second half of the trajectory and to the average all along the trajectory. By exception, for the 6 November where the first part of the trajectory had a cyclonic curvature, the three columns correspond to the second and last thirds of the trajectory and to an average over these two parts.

\begin{tabular}{|c|c|c|c|c|c|c|c|c|c|c|}
\hline Date & Centrifugal & & iolis: & & & sure & & & ind: & \\
\hline 6 Nov. & 1 & 3.0 & 1.4 & 1.9 & 0.6 & 0.6 & 0.6 & 0.6 & 0.3 & 0.45 \\
\hline 21 Nov. & 1 & 1.8 & 1.1 & 1.4 & 0.5 & 1.3 & 0.9 & & & 0 \\
\hline 22 Nov. & 1 & & & 1.6 & & & & & & \\
\hline 23 Nov. & 1 & 2.5 & 1.8 & 2.1 & 0.4 & 1.9 & 1.2 & & & 0 \\
\hline 25 Nov. & 1 & 3.2 & 4.6 & 3.5 & 0.2 & 0.4 & 0.3 & 7 & 3 & 5 \\
\hline
\end{tabular}



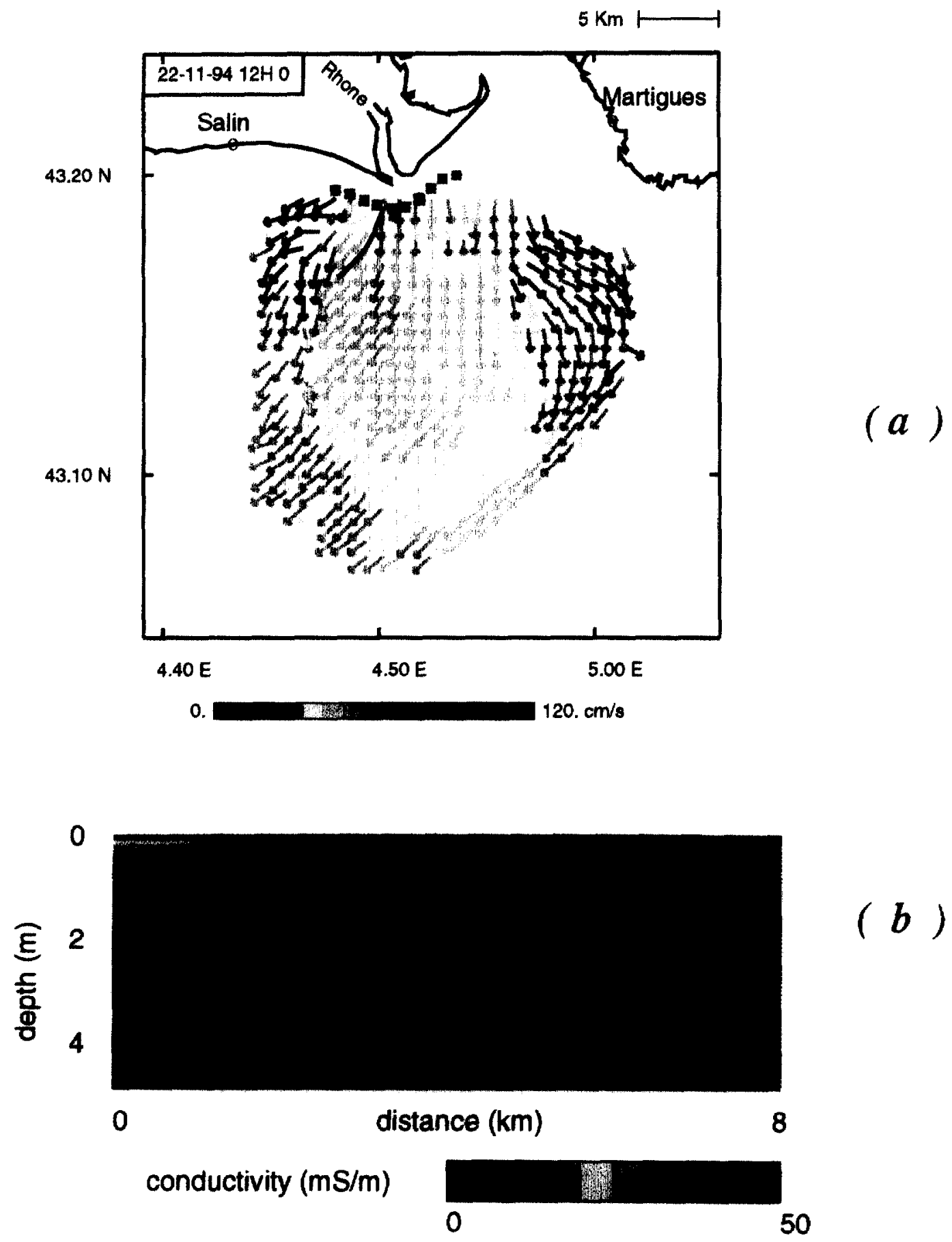

Figure 4. (a) Map of the surface current velocity at $12 \mathrm{~h}, 22$ November. Drifter trajectory is indicated by a continuous line. Black squares point out the location of the CTD profiles shown in part (b). (b) Conductivity profiles across the mouth. The horizontal coordinate is the west-east distance between the measurement point and the most western point of the transect. 


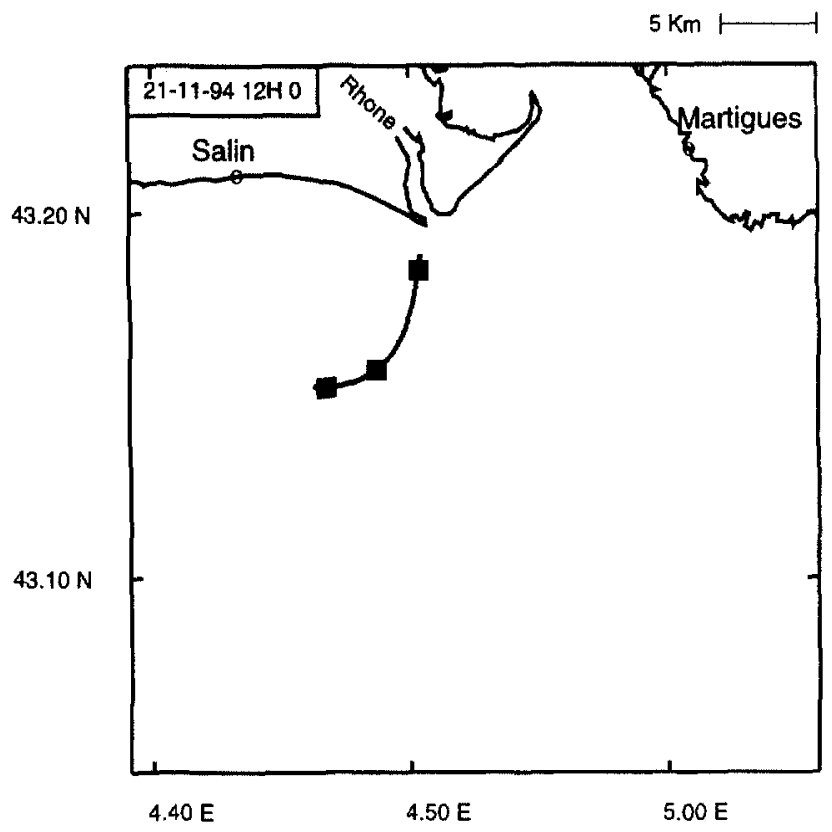

(a)

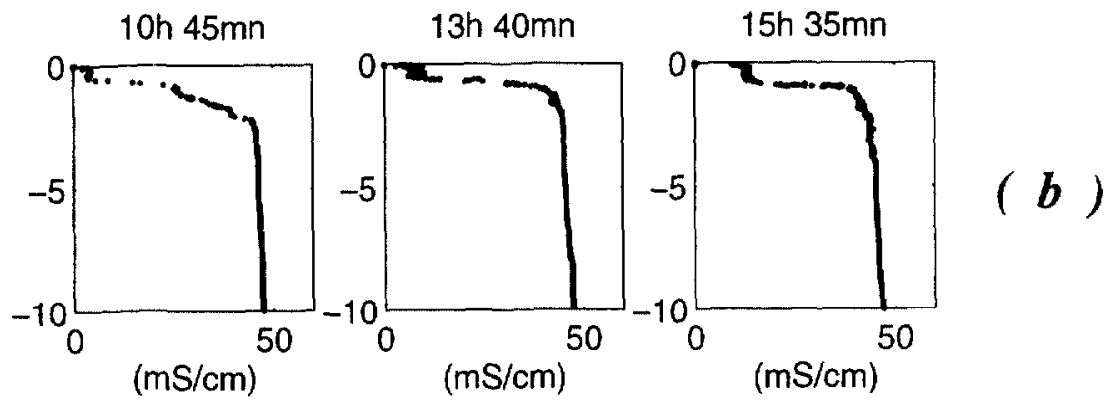

Figure 5. (a) Trajectory of the drifter on November 21. (b) Conductivity profiles at three stations along the trajectory.

result in significant variations in velocity within the plume and in the plume thickness. Between 6 and 21 November the current velocity at the same location, close to the start of the drifter trajectories, drops from 120 to $70 \mathrm{~cm} \mathrm{~s}^{-1}$ and the average depth along the trajectory is reduced from 2 to $1 \mathrm{~m}$. The ratio hetween the two products (velocity) $\times$ (thickness) $(240$ to $70=3.4$ ) is, as expected, in general agreement with the ratio of the corresponding rivers flows (7000 to $2200=3.2$ ).

Complementary data were supplied by the transverse profile of 22 November (figure $4 \mathrm{~b}$ ). The river discharge presents a maximum thickness in front of the mouth. Sharp fronts separate the plume from the ambient water, both horizontally and vertically. The transverse thickness gradient is greater on the eastern side than on the western side of the plume. The lateral extent of the plume $(6 \mathrm{~km})$ is significantly greater than the width of the river mouth (about $1 \mathrm{~km}$ ), indicating a fast transverse spreading of the flow just after the mouth. This spreading is also clearly visible on the satellite images of the plume (10 and 26 November, [11]). At the mouth itself the transverse pressure gradient force due to buoyancy effects is the dominant transverse force because of the small value of the characteristic transverse scale of the plume (comparable to the mouth width). It produces a lateral spreading which, combined to the longitudinal movement, induces the observed cyclonic curvature of trajectories whose starting point is located west of the mean axis of the plume flow and the anticyclonic curvature when the trajectory starts east of the axis. In general this spreading 
phase has already finished at the northem boundary of the radar maps. Nevertheless the gravity-buoyancy effect is expected to increase with the flow and indeed, on 6 November, both the shape of the beginning of the drifter trajectory and the corresponding part of the radar map (figure $2 \mathrm{a}$ and figure $3 \mathrm{a}$ ) show a cyclonic curvature which could correspond to the end of the process. When transverse pressure gradient forces become smaller than inertial and Coriolis forces the curvature of all the particle trajectories becomes anticyclonic. The curvature radius of the western trajcctorics is infinite at the transition from cyclonic to anticyclonic, then it decreases and correlatively the Rossby number $N_{R}$ increases. This behaviour is observed on all the trajectories: $Q_{R}=1 / N_{R}$ is always smaller in the second part of the trajectories than in the first (table 1 ).

It can be concluded that with light winds plume dynamics tend to an inertial balance after an initial phase of lateral spreading (figure 6a): the plume turns westwards, the Rossby number approaches unity and the radius of curvature tends to be equal to the inertial radius.

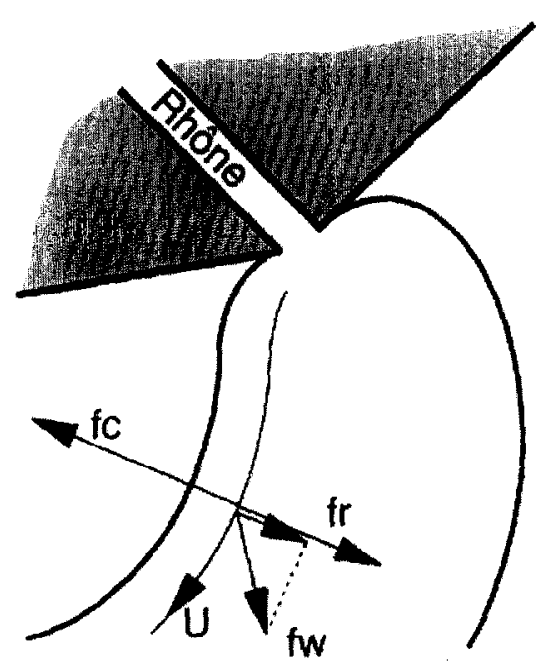

(a)
Along all trajectories a progressive reduction of the longitudinal velocity is observed (figure $3 \mathrm{~b}$ ), indicating that internal friction forces begin to play a part, enhanced by the erosion of the halocline. Progressive dilution effects increase and the Froude number decreases (table I). As it becomes less than unity (for instance at the end of the drift on 21 and 23 November), mixing forces become greater than buoyancy forces. Vertical stratification progressively disappcars, but this stage was not sampled during this experiment because it probably took place outside the range of the radar maps or of the drifter paths.

\section{INFLUENCE OF WIND VELOCITY}

On 25 November (figure 7) the flow was only slightly weaker than on 21 and 22 November $\left(1800 \mathrm{~m}^{3} \mathrm{~s}^{-1}\right)$ but a stronger wind was blowing from the north $\left(10 \mathrm{~m} \mathrm{~s}^{-1}\right)$. Very close to the mouth a thin (about $1 \mathrm{~m}$ ) surface layer of low conductivity was still present (figure $7 \mathrm{~b}$ ), but this situation rapidly changed along the trajectory. After a few

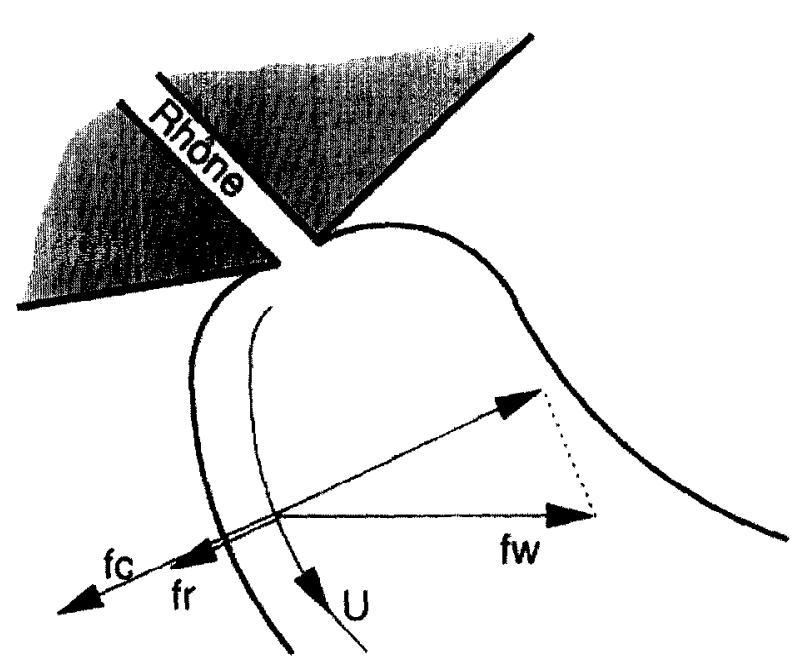

(b)

Figure 6. Sketches of the transverse equilibrium of the plume when horizontal buoyancy gradients are neglected: (a) by low winds of northnorthwest: the centrifugal force $f_{r}$ adds to the transverse component of the wind force $f_{w}$ to balance the Coriolis force $f_{c}$. If the wind is very light an inertial balance takes place. (b) by strong wersterly winds: the centrifugal force adds to the Coriolis force to balance the wind force. The trajectories are curved eastwards. 

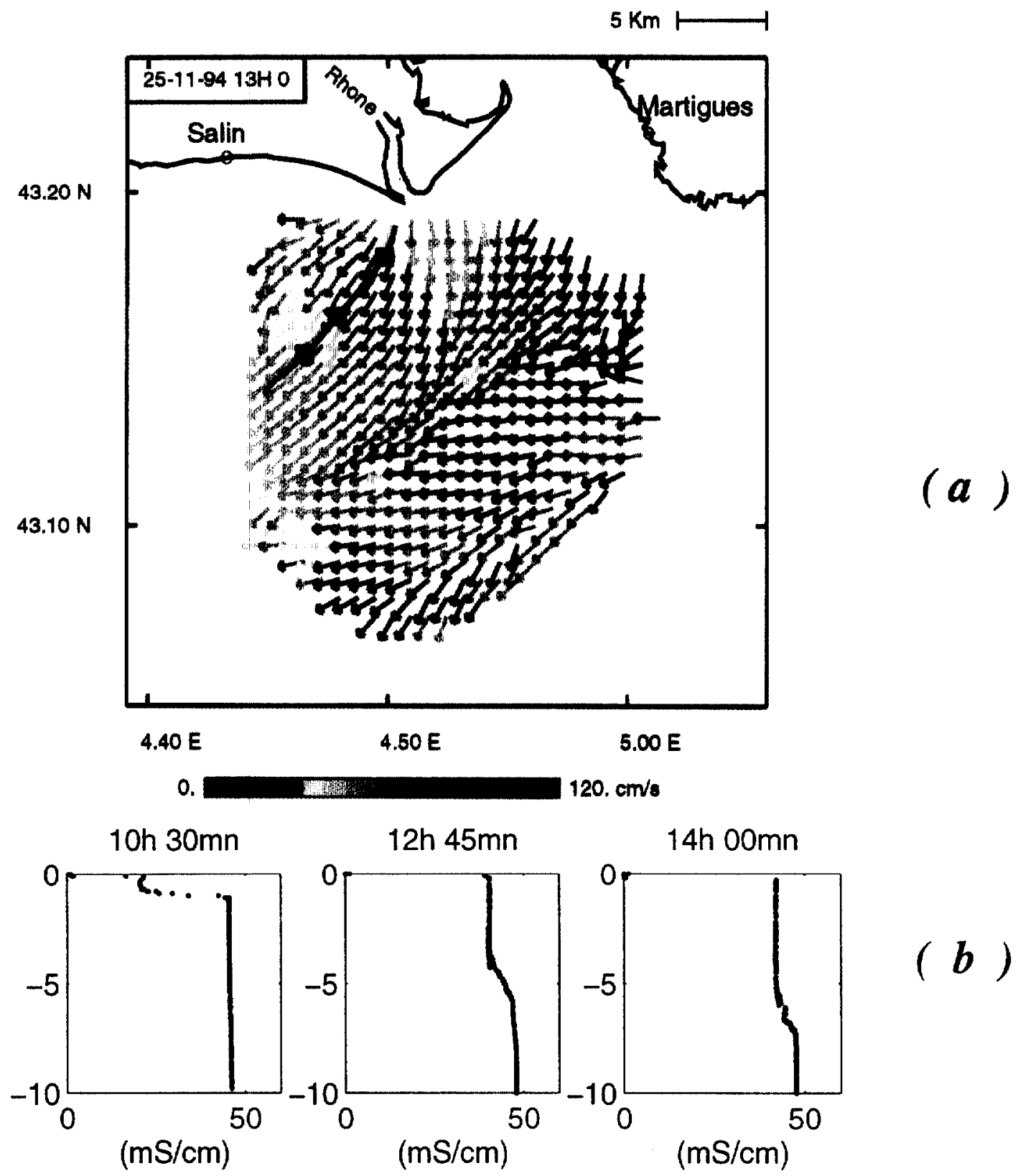

Figure 7. (a) Map of the surface current velocity at $13 \mathrm{~h}, 25$ November. Drifter trajectory is indicated by a continuous line. Black squares point out the location of the three CTD soundings shown in part (b). (b) Three profiles of conductivity along the trajectory of the drifter.

kilometers a thick ( 6 to $8 \mathrm{~m}$ ) layer of well-mixed water of conductivity hardly lower than the seawater conductivity was observed. Its thickness increased along the trajectory. This surface layer was separated from the ambient seawater by a smooth gradient of conductivity and temperature. This continuous mixing of seawater with the brackish water could be due to the influence of the waves which increase in wavelength and energy with distance from the shoreline (increasing fetch). In the last part of the drifter trajectory a mixing rate can be evaluated from conductivity profiles. Changes in conductivity and thickness show that about $2 \mathrm{~m}^{3}$ of seawater are included and mixed with 
the water present in $1 \mathrm{~m}^{2}$ of plume within an hour. Interpreting this mixing as a penetration of seawater into the plume, a vertical entrainment velocity of about $0.5 \mathrm{~mm} \mathrm{~s}^{-1}$ can be estimated.

The plume is well identified in the horizontal dimension (figure 7a) but its extension is smaller than on 21 or 22 November with similar flows and no wind. The transverse wind stress component adds to the centrifugal force to balance the Coriolis force (figure $6 \mathrm{a}$ ). The centrifugal force is then reduced, the radius of curvature is increased (which is evident on the shape of the trajectory in figure $3 \mathrm{a}$ ) and exceeds the inertial radius (the Rossby number is less than unity, or $Q_{R} \gg 1$, see table $I$ ). Other meteorological situations would give different results. For a strong westerly wind (10 November at $22 \mathrm{~h}$, figure 8 ) the centrifugal force adds to the Coriolis force to balance the wind stress (figure $6 \mathrm{~b}$ ), resulting in trajectories curved eastwards. The transition between positive and negative curvatures corresponds to almost straight and southward trajectories which are effectively observed on the maps in the morning of 10 November (and on the plume shape in the satellite image [11]).

The mixing induced by wind waves increases friction between the surface layer and the ambient water, but if the wind blows downstream as on 25 November, it increases the downstream acceleration forces. Both effects can be of a comparable order of magnitude, resulting in an only slight decrease in the velocity along the trajectory (figure $3 \mathrm{~b}$ ).

Only fairly well established situations have been analysed. The trajectory observed on 24 November is difficult to interpret within this discussion. The meteorological conditions were essentially unsteady. A rather strong wind (Mistral gust) began to blow from the west and turned to the north in the evening, which partly explains why the trajectory is so southward oriented (figure 3). CTD profiles along the drifter trajectory exhibit a complex vertical structure with several superimposed layers of different hydrological characteristics. These layers are

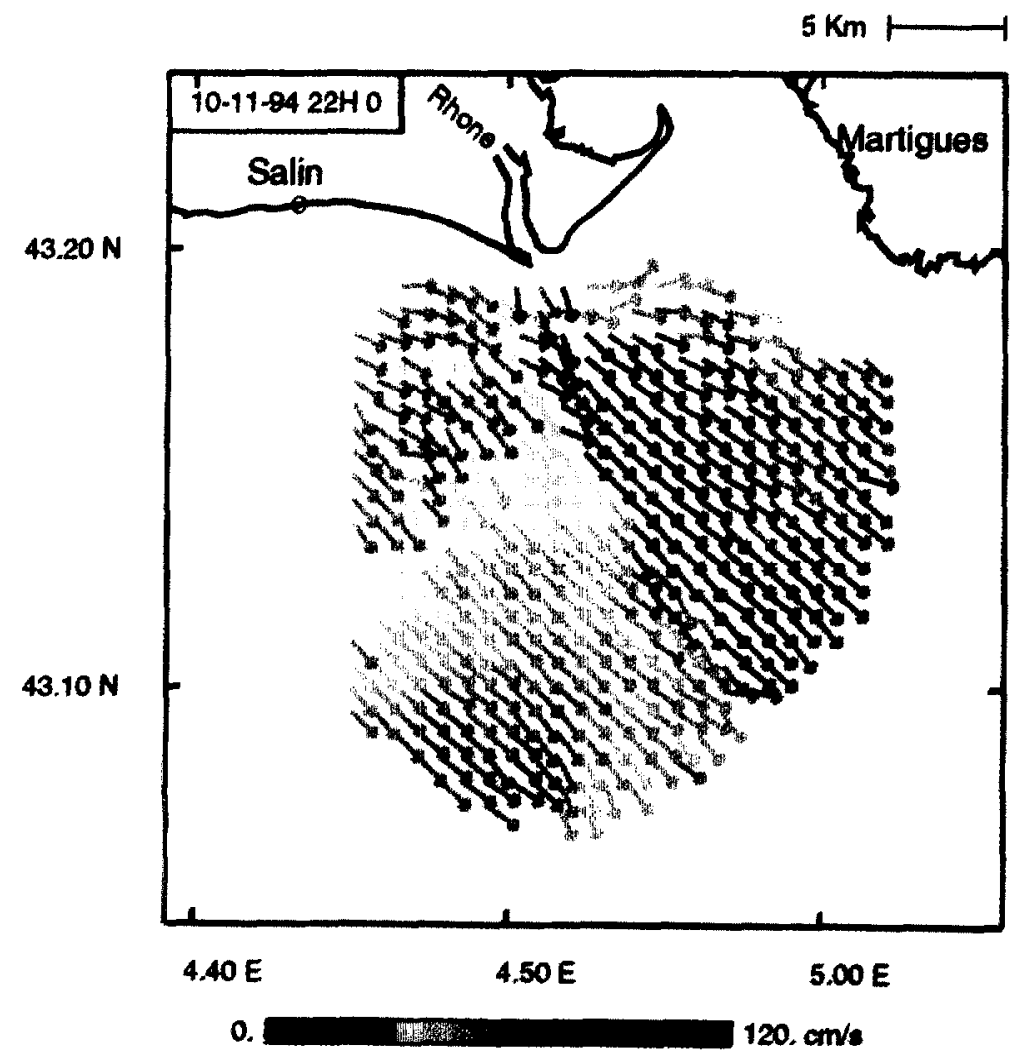

Figure 8. Map of the surface current velocity at $22 \mathrm{~h}, 10$ November. 
not present at all CTD stations. These particular vertical profiles could be due to the overlying of the thin and new spreading plume pushed by the rising wind over an older diluted structure.

\section{CONCLUSION}

The present study describes the main characteristics of the Rhone plume and the typical scales of its spatial variability. Combining radar mapping of surface current and hydrological and dynamic in situ measurements with a surface lagrangian strategy proved to be relevant for a better understanding of the key features of the phenomena.

It was shown that the plume is, in the majority of cases, a strongly buoyant structure bounded by narrow hydrodynamic and hydrological fronts. The location and the displacements of these fronts could be tracked by radar. The plume generally extends far offshore before dilution (approximately $30 \mathrm{kmi}$ ). Its location and shape are highly dependent on the meteorological and outflow conditions. The understanding of the influence of the wind on the plume was improved. There is competition between the direct action of the wind stress on the plume (acceleration, Ekman deflection) and the wave-induced mixing of marine water with the brackish plume water (friction, increase of the plume mass).

These results are important for the evaluation of the fate of inputs from the Rhone into the Mediterranean Sea. Information about the ability of light northwesterly winds coupled with a high flood episode to efficiently export far offshore relatively little diluted plume water is useful in establishing suspended material or geochemical species budgets. It should also be noted that the plume can be deflected eastwards by a strong westerly wind within a few hours.

Travelling time of the water masses in the plume stratified system before dilution becomes predominant were reported. This is of major interest in inferring the evolution of chemical species and the real nature of materials injected into the Gulf of Lions [25].

Radar maps and CTD profiles provided an extended database for the validation of the various numerical models for the Rhone plume $[2,20]$. In fact, the variations in the two-layer structure and the estimate of the mixing rate are the most important pieces of information which can improve turbulent sub-model formulation to try to account for such a strongly marked stratification or to reproduce its more or less delayed fate. The understanding and modelling of the multi-layered situations evidenced during transient episodes are doubtless chief goals for non-stationary 3D modelling. All these vertical observations, though difficult to perform because of the immediate vicinity of the surface, appear to be of sufficient interest to be carried out in future with new hydrological and dynamic measurements under a more statistically significant diversity of oceanological and meteorological conditions.

\section{Acknowledgements}

This work was supported by the Programme national d'océanographie côtière and by the European program MEDDELT (Mediterranean Deltas). The authors are indebted to J. Gaggelli and G. Rougier for their assistance in the field campaign.

\section{REFERENCES}

[1] Babin M., Therriault J.C., Legendre J., Potential utilization of temperature in estimating primary production from remote sensing data in coastal and estuarine waters, Estuar. Coast. Shelf Sci. 33 (1991) 559-579.

[2] Baeckeroot A., Devenon J.L., Modélisation du panache du Rhône, Actes du $3^{\mathrm{e}}$ colloque de Génie côtier. Sète (1994) 27 32.

[3] Barrick D.E., Evans M.W., Weber B.L., Ocean surface currents mapped by radar, Science 198 (1977) 138-144.
[4] Broche P., de Maistre J.C., Forget P., Mesure par radar décamétrique cohérent des courants superficiels engendrés par le vent, Oceanol. Acta 6(1983) 43-53.

[5] Chao S.Y., River-forced estuarine plumes, J. Phys. Oceanography, 18 (1988) 72-88.

[6] Chao S.Y., Wind-driven motion of estuarine plumes, J. Phys. Oceanography 18 (1988) 1144-1166.

17] Czitrom S.P.R., The effect of river discharge on the residual circulation in the eastern Irish Sea, Cont. Shelf Res. 6 (1986) $475-485$. 
[8] Devenon J.L., Broche P., de Maistre J.C., Forget P., Gaggelli J., Rougier G., VHF radar measurements in the Rhone river plume, Water Poll. Res. Reports. 28 (1992) 75-87.

[9] Dyer K.R., Circulation and mixing in stratified estuaries, Mar. Chem. 32 (1991) 111-120.

[10] Edmond J.M., Boyle E.A., Grant B., Stallard R.F., The chemical balance in the Amazon plume, I: the nutrients, Deep-Sea Res. 28A (1981) 1339-1374.

[11] Forget P., Ouillon S., Surface suspended matter off the Rhone river mouth from visible satellite imagery, Oceanol. Acta 21 (6) (1998) 739-749.

[12] Garvine R.W., Dynamics of small scale fronts, J. Phys. Oceanography 4 (1974) 557-569.

[13] Garvine R.W., Obscrvations of the motion field of Connecticut river plume. J. Geophys. Res. 82 (1977) 441-452.

[14] Gibbs R.J, Konwar L., Coagulation and settling of Amazon river suspending sediment, Cont. Shelf Res. 6(1986) 127-149.

[15] Kourafalou V.H, Dey L.Y., Wang J.D., Lee T.N., The fate of river discharge on the continental shelf: 1: modelling the river plume and the inner shelf coastal current, J. Geophys. Res. 101 (1996) 3415-3434.

[16] Kuparinen J., Heinanen A., Inorganic nutrient and carbon controlled bacterioplankton growth in the Baltic Sea, Estuar. Coast. Shelf Sci. 37 (1993) 271-285.

[17] Lande R., Wood M., Suspension time of particles in the upper ocean, Deep-Sea Res. 34 (1987) 61-72.

[18] Legovic T., Grzetic Z., Smircic A., Effects of wind on a stratified estuary, Mar. Chem. 32 (1991) 153-161.

[19] I ohrenz S.F., Dagg M.J., Whitledge T.F., Enhanced primary production at the plume/oceanic interface of the Mississipi river, Cont. Shelf Res. 10 (1990) 639-644.

[20] Marsaleix P., Estournel C., Kondratchoff V., Vehil R., A numerical study of the formation of the Rhone river plume, J. Mar. Systems 14 (1998) 99-115.

[21] Millot C., The Gulf of Lions' hydrodynamics, Cont. Shelf Res. 10 (1990) 885-894.

[22] Minas M., Minas H.J., Primary production in the Gulf of Lions with considerations to the Rhone river input, Water Poll. Res. Reports (1989) 112-125.

[23] Morel A., Bricaud A., André J.M., Pelaez-Hudlet J., Spatial/ temporal evolution of the Rhone plume as seen by CZCS ima- gery, Consequences upon the primary production in the Gulf of Lions, Water Poll. Res. Reports 20 (1990) 45-62.

[24] Naudin J.J., Cauwet G., Chretiennot-Dinet M.J., Deniaux B., Devenon J.L., Pauc H., River discharge and wind influence upon particulate transfer at the land-ocean interaction, Case study of the Rhone river plume, Estuar. Coast. Shelf Sci, 45 (1997) 303-316

[25] Naudin J.J., Cauwet G., Fajon C., Oriol L., Terzic S., Devenon J.L., Broche P., Experimental study of the Rhone river plume: part II: Biological processes, Oceanol. Acta, submitted.

[26] O'Donnell J., Surface fronts in estuaries: a review, Estuaries 16 (1993) 12-39.

[27] Prandle D., Matthews J., The dynamics of nearshore surface currents generated by tides, wind and horizontal density gradient, Cont. Shelf Res. 10 (1990) 665-681.

[28] Régnier P., Hoenig M., Chou L., Wollast P., Trace metals in the suspended matter collected in the mixing zone off the Rhone estuary, Water Poll. Res. Reports 20 (1990) 385-396.

[29] Sournia A., Brylinski J.M., Dallot S., Le Corre P., Leveau M., Prieur L., Forget C., Fronts hydrologiques au large des côtes françaises: les sites ateliers du programme Frontal, Oceanol. Acta 13 (1990) 413-438.

[30] Stewart R.H., Joy J.W., HF radio measurements of surface currents. Deep-Sea Res. 21 (1974) 1039-1049.

[31] Turner R.E., Rabalais N.N., Coastal eutophication near the Mississipi river delta, Nature 368 (1994) 619-621.

[32] West J.R., Oduyemi K.O.K., Shiono K., Some observations on the effect of vertical density gradients on estuarine turbulent transport processes, Estuar. Coast. Shelf Sci. 32 (1991) 365383.

[33] Williams P.J., Robinson C., Seasonal differencies in the control of productivity in the Rhone outfall region of the Gulf of Lions, Water Poll. Res. Reports 20 (1990) 9-23.

[34] Woodward E.M.S., Owens N.J.P., Rees A.P., Law C.S., A seasonal survey of nutrient cycling and primary production in the Gulf of Lions during 1988 and 1989, Water Poll. Res. Reports 20, (1990) 83-91

[35] Wright L.D., Coleman J.M., Effluent expansion and interfacial mixing in the presence of a salt wedge, Mississipi river delta, J. Geophys. Res. 76 (1971) 8649-8661. 